\title{
The Relationship between Iranian EFL Learners' Creativity and Their Lexical Reception and Production Knowledge
}

\author{
Hajilou, Y. \\ English Department, Shiraz University of Medical Sciences, International Branch, Kish, Iran \\ Tel: 98-912-297-4008Ｅ-mail: y.h.8118@yahoo.com \\ Yazdani, H. \\ English Department, Arak University, Arak, Iran \\ Tel: 98-912-426-2201_E-mail: yazdhs@yahoo.com \\ Shokrpour, N. (Corresponding author) \\ English Department, Shiraz University of Medical Sciences, Shiraz, Iran \\ Tel: 98-917-316-2815 E-mail: shokrpourn@gmail.com
}

Received: November 16, 2011

Accepted: December 21, 2011

Published: March 1, 2012

doi:10.5539/elt.v5n3p131

URL: http://dx.doi.org/10.5539/elt.v5n3p131

\begin{abstract}
This study aimed to determine the relationship between creativity on one hand and lexical reception and production knowledge of Iranian EFL students on the other hand. The data were collected using three tests: a creativity test (Torrance, 1990), the Vocabulary Levels Test (Schmitt, Schmitt, \& Clapham, 2001), and the Productive Version of the Vocabulary Levels Test (Laufer \& Nation, 1995) which were administered to a group of 141 Iranian undergraduate students majoring in English Translation and Literature at Arak and Qom universities. The results demonstrated that there was not a high correlation between creativity on one hand and lexical reception and production on the other hand. The learners' passive and active vocabulary knowledge in the tests as a whole and at different word-frequency level were highly correlated. Passive vocabulary was always larger than active vocabulary at all levels; however, the gap between the two increased at lower word-frequency levels.
\end{abstract}

Keywords: Creativity, Receptive vocabulary, Productive vocabulary, Vocabulary size, Depth, Frequency

\section{Introduction}

Whether it is done because of personal interest or professional obligations, learning a different language is a difficult work. Improving semantics while at the same time developing lexis are not easy to handle. On the other hand, in most of the recent research in the area of SLA, examining the variables that have been found to be significant in personality psychology seems to be a trend. In addition to motivation, anxiety, learning styles and strategies which are clearly-defined variables, it seems that other constructs are entering into this research area as well (Albert, 2006). Dörnyei (2005) highlights the importance of studying the conventional psychological variables such as personality, self-regulation, self-esteem, and creativity which are considered as individual differences. Researchers are implicitly or explicitly involved in language teaching, teacher training, or the development of SLA theory. Yet, in comparison, there are relatively few references to cognitive and psychological factors in SLA studies.

The relationship between SLA and individual differences has been investigated by many scholars (Altman, 1980; Dörnyei, 2005; Ellis 1994; Larsen-Freeman \& Long, 1991; Segalowitz, 1997; Skehan, 1989). Segalowitz (1997) defined seven categories of individual differences, two of which are 'creativity' and 'motivation'. Concerning the individual learner differences, the present study works on the creativity level as one variable on one side of the research continuum, and on the other side on the domain of receptive and productive vocabulary size in the context of Iranian EFL learners.

Creativity is difficult to define. One of the difficulties in defining the concept of creativity is the existence of different relevant notions such as the creative performance or product, the creative person, the creative situation, the creative process, and creative potential (Brown, 1989; Han as cited in Hsen, 2011; Lubart, 1994; Torrance, 1984). 
Due to the wide range of topics to elaborate on and lack of space we would present no theories regarding creative process or creative products (Finke, Ward, \& Smith, 1992). As a result the current research will concentrate on creative potential only, which is "the cognitive underpinnings of the creative working of the mind" (Albert \& Kormos, 2011: 75)

In Kneller's argument (quoted in James 1999), creativity is characterized by two factors, i.e. novelty and relevance. The first refers to the arrival of something new or original, and the second characteristic, relevance, reminds us that creativity is always in a context and a creative act is a response to a situation in which something requires a solution or at least clarification. Matsouka, Trevlas, \& Zachopoulou (2003) declare that creativity is a multidimensional construct and may be measured as a personality trait or a creative style. Abutalebi \& Costa (2008), who investigated the role of creativity in entrepreneurship education, specify creativity as a unique ability of individuals and the undiscovered mystery of the brain as well.

Hadley (2003) was one of those who have reported the significance of the creativity effect in learning a second/foreign language and language use creatively. He maintains that students, who hope to make progress in their skills beyond the elementary phases, must learn to create with the language, or in other words make use of language creatively. In fact, E. Paul Torrance - who is well-known as the 'Father of Creativity' due to his nearly 60 years of research - has become the framework for the field of creative education and creative thinking tests (Kim, 2008). In Clapham (2004), Kim (2008) and Sternberg's (1985) justifications, Torrance Tests of Creative Thinking, hereafter (TTCT), which are combined with longitudinal studies, enhanced creativity awareness, improved teaching techniques, and highlighted the field of creativity.

However, unlike creativity, the lexis is an essential contributor whose role in FLA and SLA has been continuously admitted (Hunt \& Beglar 2005; Lewis 2000; Wilkins 1972; Zimmerman 1997). In learning English language, vocabulary and lexical knowledge is acknowledged as a significant contributor to ESL or EFL improvement (Coxhead, 2006; Horst, Cobb, \& Nicolae, 2005; Lee \& Munice, 2006). That is, "L2 learners' lexical knowledge may determine the quality of their listening, speaking, reading, and writing performances" (Mokhtar, 2010: 72).

Laufer \& Goldstein (2004) point out that vocabulary knowledge is not an all-or-nothing phenomenon but involves degrees of knowledge. The majority of researchers affirm that they should consider lexical knowledge as a continuum which consists of various levels and dimensions of knowledge, initiating with superficial familiarity with a word form and finishing with the ability to apply the vocabulary appropriately in free production (Laufer, 1998; Meara \& Alcoy, 2010).

Vocabulary has been categorized in different ways by different researchers (Henricksen, 1999; Nation, 2001; Qian, 2002). Henriksen (1999) classified lexical knowledge into three categories of 'partial vs. precise', 'shallow vs. deep' and 'receptive vs. productive'. According to what Henriksen (1999) declares, the receptive-productive dimension is used as a bridging dimension between lexical competence and performance. Although vocabulary has been defined by many categorizations, the focus of this study is basically on the analysis of lexical knowledge from two scopes, (a) receptive vs. productive, and (b) size vs. depth.

As to the distinction between receptive and productive knowledge of vocabulary, Nation (2001, 2005), Read (2000) and Schmitt (2000) have postulated that receptive vocabulary knowledge is the knowledge to understand a word in listening and reading, whereas productive vocabulary knowledge is the knowledge to produce a word when one speaks and writes. Researchers in the field of L2 vocabulary acquisition use the terms 'receptive' and 'productive' as synonymous with 'passive' and 'active', respectively (Meara \& Jones, 1990; Corson, 1997; Laufer, 1998, all cited in Nation, 2001).

Size and depth are another division of lexical knowledge (Anderson \& Freebody, 1981; Meara, 1996; Zareva, Schwanenflugel, \& Nikolova, 2005). Vocabulary size is also called breadth, which is a quantitative dimension of vocabulary knowledge. It refers to "the number of words for which the person knows at least some of the significant aspects of meaning" (Anderson \& Freebody, 1981, p. 93). Vocabulary depth is a qualitative dimension of vocabulary knowledge and refers to the degree to which a learner knows a certain word in addition to knowing a primary meaning (Qian, 1999, 2002, 2004).

Regarding the significance of size and depth, the former which is basically knowledge of a primary meaning and a form of a word has been regarded as the most vital aspect of vocabulary knowledge (Laufer, \& Goldstein, 2004; Laufer \& Goldstein, 2004; Webb, 2005). Nation (2001) concentrates on one determining and inseparable feature in the lexical discussions, called the 'frequency of the lexical item'. We all encounter some words more often than others. Also, we all use some words more than others and there are some words in our native tongues that we never use at all (Alderson, 2007). A study of word frequency counts reflected that knowledge of the 2,000 most frequent word families must be provided for basic oral communication (Schonell \& Stephens, cited in Nation, 1990). As Nation 
(1990) justifies, these 2,000 word families make up about $87 \%$ of written texts and about $80 \%$ of typical academic texts. Additionally, in Hazenberg \& Hulstijn's (1996) estimations, a lexical base of about 10,000 word families is needed at least to study at the university level which is half of what an average adult native speaker knows.

The inseparable feature of lexical knowledge is lexical assessment, and one of the issues that have been focused regarding vocabulary testing is the distinction between receptive and productive vocabulary. It was reflected that The EVST (Eurocentres Vocabulary Size Test), VLT (Vocabulary Levels Test), and VKS (Vocabulary Knowledge Scale) are receptive vocabulary tests. Nation $(1993,1990)$ presented the Vocabulary Levels Test, hereafter (VLT), as a measuring tool for the learners' size of lexical knowledge. According to Schmitt et al. (2001, p. 58), "the VLT provides a profile of a learner's vocabulary, rather than a single figure estimate of overall vocabulary size". There are other receptive vocabulary tests such as Yes/No Vocabulary Test (Meara \& Buxton 1987; Meara \& Jones 1990), Revised Edition of the Vocabulary Level Test (Schmitt, Schmitt, \& Clapham, 2001) and ADELEX Levels Vocabulary Test (ALVT) (López Mezquita, cited in Liach \& Gallego, 2009) that are valid ones.

Laufer (1998) divides productive vocabulary into 'controlled production' and 'free production'. The PVLT is a productive vocabulary test which is also called 'controlled productive vocabulary test'. There is another test called Lexical Frequency Profile (LEP) which is also named as 'Free Productive Vocabulary Test' by Laufer and Nation (1995), in which written or spoken discourse produced by the subjects are analyzed and the vocabulary use is ranked into frequent and infrequent words. There are other PVLTs called LFP-Lexical Frequency Profile (Laufer \& Nation, 1995) and Lex30 (Meara \& Fitzpatrick, 2000) which have been proved to be reliable ones for the assessment of lexical knowledge.

Recently, some research studies measuring receptive and productive vocabulary size have been conducted by Fan (2000), Laufer (1998), Laufer \& Paribakht (1998), Morshedian (2008), Nemati (2010), Waring (1997) and Webb (2008); these studies have mainly addressed receptive and productive vocabulary size, but some differences in their research instrumentation and the scoring systems are observable.

In summary, the three most widely-used vocabulary breadth tests, the EVST, VLT, and PVLT, were used as the measuring instruments of the present study. Of the three, the PVLT and VLT were selected to measure the productive and receptive vocabulary size, respectively. According to Laufer \& Nation (1995:312) "the PVLT also stands out in terms of its format because it requires the student to produce the word as they would if they were speaking or writing, and thus seems to more realistically mirror natural language use". Moreover, the PVLT has been made available on the internet and a pen and paper version of the test can easily be administered in class. Therefore, the PVLT was determined to be the most suitable instrument for the present study. Meara \& Alcoy (2010) have also proved the suitability of VLT recently.

\section{Significance of the Study}

The number of studies on receptive/productive vocabulary distinction is much more than the size of research on the relationship between psychological factors and reception and production of words. In several studies, it has been reported that there is a relationship between proficiency and vocabulary size of L2 learners (Ottó, 1998), but no point is directed toward creativity. The present study takes a step toward the clarification of whether the psychological parameter of creativity plays any significant role in productive/receptive vocabulary learning.

\section{Research Questions}

Regarding the reviewed literature, the present study tends to answer the following research questions:

1. Is there any significant correlation between creativity of Iranian EFL learners and their lexical reception knowledge?

2. Is there any significant correlation between creativity of Iranian EFL learners and their lexical production knowledge?

3. What is the difference between the passive and active vocabulary sizes of Iranian EFL learners in creativity groups?

\section{Material and Method}

\subsection{Participants}

A total of 141 Iranian learners of English, majoring in either English literature or English translation at Arak and Qom State Universities participated in this study. 87.9\% (124) of the participants were females and 12.1\% (17) were males. The ratio of female to male students truly reflects the population, where the number of female students is growing in the academic settings of Iran. The ages of the participants ranged from 18 to 31 years old, with the average of 24 and they were in different levels of proficiency. 


\subsection{Instruments}

\subsubsection{Torrance Test of Creative Thinking (TTCT)}

To measure the creativity levels of the participants, TTCT (Torrance, 1990) was administered. This test has been widely used in different educational studies and its reliability is reported to be 0.80 (Fasko, 2001). The test has been translated into Persian at Allame Tabatabaiee University by Tahmasebi (1999) who reported Cronbach alpha of 0.77 for the Persian version of TTCT. The test consists of 60 questions each followed by three choices that include different hypothetical situations of responding for the participants. As ranked by the scale of the test itself, the sum of total scores is categorized as "low $=$ up to 75 ; mid $=76-85$; high $=86-120$ ". In the present study the scores ranged from 44 to 115. In data coding, 0 was considered for low, 1 for medium, and 2 for high levels of creativity. The time allocated for this test to be done is 30 minutes.

\subsubsection{Vocabulary Levels Test (Test B)}

The Vocabulary Level Test (VLT) used in this study was the second version of the levels test revised and validated by Schmitt et al. (2001). It provides an estimate of vocabulary size at 2000, 3000, 5000, and 10000 frequency levels and also provides an estimate of the size of the examinee's academic vocabulary (UWL). In this version, there are 10 clusters at each level and each cluster has six words and three definitions. The test has 150 items and test takers are supposed to match the definitions on the right in each cluster with the corresponding words on the left. There are 15 nouns, 9 verbs, and 3 adjectives in each word level with a ratio of 3: 2: 1, so there are 75 nouns, 50 verbs, and 25 adjectives assessed in the whole test. The validity and reliability of the test were proved by Schmitt et al. (2001) and the reliability of the different levels of version 2 ranged from 0.92 to 0.96 .

\subsubsection{Productive Vocabulary Level Test (Test A)}

The Productive Version of the Vocabulary Levels Test (PVLT) is a diagnostic test developed by Laufer \& Nation (1995). The PVLT or Controlled Active Vocabulary Size test (Laufer \& Nation, 1995) also measures vocabulary knowledge at the same five levels as the passive version does. It is a valid test being used in many studies and its reliability is reported to be 0.93 by its authors. Each of the five frequency levels of the PVLT is represented by 18 items on the test, making 90 questions totally. This test had 13 common words with the passive version; 6 in the 2000 level, 3 in the 3000 level and 4 in the academic level (UWL). Here the test takers read a sentence from which a word has been omitted. The beginning letters of the words have been provided to prevent the use of non-target words. The students are supposed to provide the missing letters in each word in the space provided on the answer sheet.

\subsection{Procedures}

In the first step, a valid creativity test (TTCT) was administered to measure the creativity levels of the participants. A week after the administration of these tests, the second step of this study that was the administration of VLT was performed in order to clarify the lexical reception size of the participants. In order to carry out the last phase of data collection, PVLT was held a week later in order to reduce the effect of remembering words from VLT by the participants. To control the effect of administration time, all the tests were given to the students during their regular class time.

\section{Results and Discussion}

\subsection{Performance on the Torrance Test of Creative Thinking}

The descriptive statistics of the test are displayed in Table 1. Minimum score of this test is 44 and the maximum score is 115 out of 120 . (mean =79.36), which according to the scale of the level categorizing, belongs to the medium level, accompanied with the standard deviation of 13.63 .

\section{[Insert Table 1 Here]}

Regarding the frequency of the scores in each creativity level, i.e. Low, Medium and High, their frequency and percentage were measured. (Table 2 and Figure 1)

[Insert Table 2 Here]

As it is clear, $36.20 \%$ of the participants had Low level of creativity, $29.1 \%$ had Medium creativity level and $34.80 \%$ of the participants enjoyed having High creativity level. The number of high and low creative students is almost the same.

\section{[Insert Figure 1 Here]}

Table 3 shows the descriptive statistics of each level. Participants with 'low creativity' level or 'Low creative' 
participants, (LC) hereafter, showed a mean of 66.28 and standard deviation of 6.66. Those with 'Medium creativity' level or 'Medium creative' participants, $(\mathrm{MC})$ hereafter, had a mean of 78.43. (standard deviation= 4.41) The participants with 'High creativity' level or 'High creative' participants, (HC) hereafter, had a mean of 94.20, and the standard deviation of 7.11 .

[Insert Table 3 here]

The scores of TTCT were also compared, aiming to determine if there was any significant difference between the three groups of creativity levels. We used non-parametric counterpart, i.e. Kruskal-Wallis one way ANOVA. The results indicated that there was a statistically significant difference between the three creativity levels $(\mathrm{H}(2)=$ $120.618, p=.000)$ at .05 level of significance, with a mean rank of 27.30 for LC, 70.38 for MC, and 117.00 for HC participants.

Consequently, we rejected the null hypothesis that all three groups' means are equal, since $p(.000)<\alpha$ and we conclude that at least one of the group means is significantly different from the others. In order to know where the exact differences are, we used Tamehane's test instead of Man Whitney test, "on the account that the number of samples in each variable level is not the same" (Mehotcheva, 2008:9). As shown in Table 4, the LC group $(M=$ $65.84)$ is significantly different from the MC group $(M=78.44)$, with a mean difference of -12.59 and a $p$ value of .000. Also, the LC group $(M=65.84)$ is significantly different from the HC group $(M=94.20)$, with a mean difference of -28.36 and a $p$ value of .000. Regarding the MC and HC groups, as it is obvious from the Table, the MC group $(M=74.88)$ is significantly different from the HC group $(M=94.20)$, with a mean difference of -15.76 and a $p$ value of .000 .

[Insert Table 4 Here]

\subsection{Performance on Vocabulary Levels Test and Productive Vocabulary Levels Test}

The results of VLT and PVLT are set forth in Table 5. The minimum scores obtained by the participants on VLT and PVLT were 38 and 11, respectively. The obtained maximum score of the former was 138 and 80 for the latter. The mean of VLT was 95.76 with the standard deviation of 23.133 which reflects a wide range of scores around the mean. Median by the value of 98.00 and mode by 97 are not too far away from the mean, but they do not coincide either.

[Insert Table 5 Here]

Schmitt et al. (2001) reported that learners acquire more frequently-used words before they acquire less frequently-used ones. In other words, they found that the five frequency sections of the VLT are quite scalable; that is, if a learner has mastered one level, it can be assumed that (s)he has reached the criterion mastery at the higher frequency levels.

[Insert Table 6 Here]

A look at Table 6 also hands on that the results obtained on VLT are quite scalable, too. The means of the different passive and active word levels decrease progressively as one goes down to lower word frequency levels. The means for the passive version at the 2000,3000,5000, UWL and the 10,000 word levels were 27.38, 23.60, 22.76, 16.91 and 5.10, and those for the PVLT were 14.14, 9.22, 9.00, 9.06 and 3.32, respectively. The means of the UWL sections neatly fit between the 3000 and 5000 word levels in both passive and active tests in this research. However, Schmitt et al. (2001) claim that the words in the Academic section are not primarily frequency driven and that they can be placed anywhere between the 2000 level and the 10,000 level. The mean of the total VLT in percent was 63.84 and that of the total PVLT was 49.85 .

The active-to-passive ratio turned out to be 46.21 percent, based on which we can make the conclusion that the participants' passive vocabulary was larger than their active vocabulary. In other words, the learners could not use all the words they knew productively, indeed only $46.21 \%$ of them were employed in production. These results are in line with the findings of Aitchson (1987), Clark (1993), Laufer (1998), Laufer \& Goldestein (2004), Schmitt et al (2001), Webb (2008) and Meara \& Alcoy (2010) who all reported that passive vocabulary size is always larger than active vocabulary size.

\subsection{Passive and Active Vocabulary Levels}

In this study, in addition to considering the vocabulary size of the participants as a whole and at different word levels, we examined the passive and active levels of the participants as a whole by two formulas offered by Laufer (1998). To estimate the participants' passive and active vocabulary levels, Laufer's (1998) following procedures were applied: 


\section{Passive Vocabulary Level}

$((2000$ passive score $* 2)+3000$ passive score + Academic vocabulary score +5000 passive score $+((3000$ passive score +5000 score $) / 2)+((5000$ passive score +10000 passive score $) / 2 * 4)+10000$ passive score $) / 330 * 10000$

\section{Active Vocabulary Level}

$((2000$ active score $* 2)+3000$ active score +5000 active score + University Word List score $+((3000$ active score +5000 active score $) / 2)+((5000$ active score +10000 active score $) / 2 * 4)+10000$ active score $) / 198 * 10000$

The descriptive statistics of the participants' passive and active vocabulary levels are demonstrated in Table 7. In line with the reports of Laufer (1998) and Golkar \& Yamini (2007), it is evident that the participants enjoyed higher passive lexical level $(M=4347.64)$ than active $(M=2514.03)$ vocabulary level.

[Insert Table 7 Here]

As claimed by Laufer \& Goldstein (2004), it shows that passive knowledge of the words is a more advanced form than active knowledge.

\subsection{Creativity and the Passive Lexical Knowledge}

One of the main questions of this study was investigating the possibility of any significant correlation between creativity and passive lexical knowledge by Iranian EFL learners. In order to answer this question, a Pearson Product Moment correlation was run between the two variables, i.e. creativity and lexical reception. Creativity was measured by TTCT and lexical reception was evaluated by VLT. As it is evident from Table 8, the correlation was significant at the 0.05 level. The correlation coefficient $(\mathrm{r}=0.259, p=.002)$ uncovers that there was a positive relationship between creativity and passive vocabulary knowledge, and although it was statistically significant, this relationship was not strong. As a result the first hypothesis of this study which holds that there is no significant correlation between creativity of Iranian EFL learners and their passive lexical knowledge is rejected.

[Insert Table 8 Here]

\subsection{Creativity and Active Lexical Knowledge}

To answer the second research question, the same formula was applied for two variables, i.e. creativity and lexical production. Lexical production was evaluated by PVLT. As it is evident from Table 9, the result was significant at the 0.05 level.

\section{[Insert Table 9 Here]}

The correlation coefficient $(\mathrm{r}=0.279, \mathrm{p}=.002)$ illustrates that there was a positive relationship between creativity and active lexical knowledge, and although statistically significant, it was not a strong relationship. As a result, the second hypothesis of the study would be rejected as well since $p<\alpha$.

The correlations were also observed between creativity on one hand and passive and active 'levels' on the other hand. The Pearson Correlation coefficient between creativity and passive 'level' turned out to be $(\mathrm{r}=0.272, p=.001)$ and that between creativity and active 'level' was $(\mathrm{r}=.274, \mathrm{p}=.001)$ at .01 level of significance. Although creativity and active / passive 'levels' were positively correlated and statistically significant, there were not strong correlations between them. As it is statistically apparent, the correlation between creativity and active knowledge was a little more than creativity and passive knowledge. This report can be indirectly supported by Albert \& Kormos (2004) who say that, creativity is usually illustrated in production that is in creative products. Its effects are more probably traceable in output. Actually creativity requires a response which includes both feeling and thinking. Swain (1985) declares that tasks that involve the use of imagination and the generation of new ideas might provide creative students with more chances to practice, that is, to produce more comprehensible output, which could lead to greater success in second language acquisition. This suggestion can be generalized to the domain of lexical knowledge since vocabulary is a part of SLA. As a result creativity by its tasks may be highly correlated with lexical reception and production. It is also supported by the reports of Ottó (1998), indicating a significant positive correlations between different measures of students' creativity and their end-of year English grades.

\subsection{The Difference between Participants'Passive and Active Vocabulary Size in Creativity Groups}

To answer the third research question of the study, three creativity groups' passive and active vocabulary sizes were compared in the tests as a whole and at different word frequency levels. We used one way ANOVA to compare the means. The results of Kruskal-Wallis one way ANOVA revealed that in passive 2000 level, there was not a significant mean difference between three creativity groups $((\mathrm{H}(2)=4.300, p=.116)$. It may be concluded that since lexical knowledge of 2000 word level was almost equally available for all the participants, we might consider creativity as a determining factor. However, for the other word levels and also for active and passive 'levels', it is 
clear that the differences were significant. Subsequently, the conclusion that at least one of the creativity groups' lexical means was significantly different from the others was made. Moreover, Tamehane's post hoc test specified the place of differences.

As to the difference between passive and active lexical knowledge in LC and MC groups, the results indicated that in passive section, the lexical mean difference between these groups in total passive, academic level, and 10000 level was significant $(p<.048)$. In other words, it could be suggested that creativity affects lexical passive knowledge at total passive, academic and 10,000 levels, in the case that having LC or MC levels might be influential. Academic and 10,000 levels were two difficult levels for the participants but it seems that MC participants knew more vocabulary at these levels than their LC counterparts. In total passive part also the MC participants were more capable in lexical knowledge than those in LC group; however, the lexical mean difference was not significant at 2000, 3000, and 5000 levels $(p>.138)$ since $p>\alpha$, and the LC and MC participants had nearly equal lexical means in these levels.

As to the active section, the difference between the lexical means was significant between LC and MC participants in total active, 5000, and 10,000 word levels $(p<.038)$. It means that at these levels, the participants in the MC group knew a lot more words than LC participants. So, we may report that creativity influences the participants' performance in these levels. Meanwhile, no significant lexical mean difference in active 2000, 3000, and academic levels $(p>.120)$ was observed, since $p>\alpha$. Subsequently, the null hypothesis that LC and MC participants had equal lexical means in these levels would not be rejected. In other words, it seems that creativity did not affect lexical active knowledge at 2000,3000, and 5000 levels; and having LC or MC does not impact any result.

By reviewing the results, we concluded that 2000 and 3000 levels in both active and passive sections had insignificant mean differences, the reason of which may be the fact that these two levels have the highest frequencies and the majority of the participants were lexically capable in these levels. 10,000 level in both active and passive parts had a significant mean difference, in the case that it was the lowest frequency level among the other word levels. Academic level in passive part had a significant mean difference, while in active part the difference was not significant. A possible reason may be the fact that passive vocabulary is always larger than active lexical knowledge and also academic participants are more frequently encountered with academic terminology than other words. In fact, academic words are much more available to the participants in their courses of study. Both total passive and active sections had a significant mean difference. In a word, we may claim that creativity makes difference for LC and MC groups in total passive and active lexical knowledge as a whole but not for all word levels independently.

According to the results, no significant difference was perceived between MC and HC participants in any word level $(p>.685)$. It seems that creativity did not affect lexical active and passive knowledge in participants with MC and $\mathrm{HC}$ levels. Furthermore, the slightest differences were observed in active 5000 and 10,000 levels with the mean differences of 0.067 and 0.029 , respectively. So the MC and $\mathrm{HC}$ participants had the nearest lexical means in these levels.

There was a significant difference between the HC and LC participants' passive vocabulary knowledge in the test as a whole $(p<.010)$ and at each separate word level $(p<.045)$ except one. Their active vocabulary sizes were also significantly different in the test as a whole $(p<.005)$ and at all frequency levels $(p<.021)$. So, the HC participants knew a lot more vocabulary items than their LC counterparts. The only exception was the difference between their passive vocabulary size at 2000 word level which was not significant $(p=.286)$. An investigation of the participants' performance on this part of the test revealed that the insignificant result might be due to the fact that passive 2000 word level is too easy and frequent for the HC and LC participants alike, so both groups could perform well on this section, and hence the insignificant difference was observed.

Figures 2 and 3 illustrate these differences graphically.

[Insert Figure 2 Here]

[Insert Figure 3 Here]

Figure 3 illustrates the changes in lexical active knowledge in three creativity groups. The same as passive section, the nearest and the best performances in three creativity groups belonged to 2000 level which was the highest frequency one among the other word levels. We had a sharp fall in 3000 level concerning 2000 level by about $26 \%$, $27 \%$, and $30 \%$ in $\mathrm{HC}, \mathrm{MC}$, and LC groups, respectively. While HC participants'academic lexical knowledge was more than their 5000 level's (about 3\%), for MC and LC participants this academic knowledge was less than their 5000 levels (about $1.5 \%$ and $1 \%$, respectively). The sharperst drop in vocabulary size percentage occured in 10,000 level concerning the academic level for LC (30\%), MC (31\%), and HC (35\%) creativity groups. HC participants 
outperformed their LC and MC counterparts in all word levels except one. Contrary to the common sense of expectation, MC participants were able to produce more words at 10,000 word level than their HC counterparts. Again the possible justification for this can be the fact that there was not a strong correlation between creativity and active test scores as a whole. But altogether $\mathrm{HC}$ participants were better lexical producers than participants in $\mathrm{MC}$ and LC groups.

There were also dramatic changes in passive and active 'levels' in three creativity groups. Table 10 manifests the descriptive statistics and the post hoc results of these levels in three creativity groups.

\section{[Insert Table 10 Here]}

There were significant differences between LC and MC participants and also between LC and HC participants in passive 'level' $(p<.033)$ with a mean difference of -739.93 , and -895.25 , respectively. The only insignificant difference was between MC and HC participants ( $p>.948$ ), with a mean difference of -155.31 , with $p>\alpha$. So, MC and HC participants had higher passive levels than their LC counterparts. In the active level there was a significant difference between LC and MC participants and also between HC and LC participants $(p<.033)$ with a mean difference of -806.90 and -964.75 , respectively. In the passive 'level', the only pairs whose mean difference did not have a significant difference was MC and HC participants $(p>.965)$, with a mean rank of -157.85 , with $p>\alpha$. The most observable difference occurred between LC and HC participants in the active level. This finding may suggest that $\mathrm{HC}$ participants were more able in lexical production than the participants in LC group. The slightest difference was observed between MC and $\mathrm{HC}$ participants, with a mean difference of -155.31. It seems that the participants at this pair had the same passive lexical level.

\section{[Insert Figure 4 here]}

Also, as shown in Figure 4, passive level in all creativity groups was larger than active level. This may be concluded by the findings of Fisher (2003) who asserts that,

Creative attitude encourages students to be curious, take risks, use complex ideas and experience the imagination. Cognitive factors and skills allow the students to generate process and play with ideas. If the activation of learners' creativity and its usage are proved to be effective on the guessability of unknown words, then teachers of English should pay more attention to the creativity activation of their students and their roles in improving the students' comprehension dealing with unknown words. (p. 76)

\section{Conclusion}

Our experiment had the advantage of involving L2 learners at three creativity groups which allowed for finer generalization concerning the quality of their vocabulary knowledge. The frequency of TTCT scores showed that $36.20 \%, 29.10 \%$, and $34.80 \%$ of the participants had LC, MC, and HC levels, respectively, i.e. the highest frequency was devoted to participants with low creativity. It was also supported that the performances of participants in three creativity levels were significantly different.

Concerning the breadth test results, there was a tendency in the production of correct answers according to the level of word frequency. In this way, 2000 word level obtained the highest scores in VLT, followed by 3000, 5000, then academic, and finally 10,000 word levels. Regarding PVLT, the 2000 word level presents the highest mean of correct responses, followed by 3000 , academic, then 5000 , and finally 10,000 levels. In this breath test, the participants' lexical knowledge in academic level was higher than their knowledge of words in 5000 level which reflected the greater degree of participants' familiarity with academic words in production. This tendency, i.e. less correct answers in the lower levels of word frequency, can be explained by the fact that words specific within register are more problematic than general ones, since general words are more common than specific lexical items, thus being more frequent (Segler, 2001). Also, in line with the previous findings, measuring the passive and active 'levels' of the participants by Laufer's (1998) formula demonstrated that learners enjoyed having higher passive 'level' than active 'level'.

Regarding the relationship between creativity of Iranian EFL learners on one hand and their lexical reception and production knowledge on the other hand which are the two main questions of this study, it was revealed that there were positive significant correlations between creativity and lexical reception and production $(\mathrm{r}=.259, p=.002 / \mathrm{r}$ $=.279, p=.002$ for passive and active tests, respectively). Although these correlations coefficients were statistically significant, they were not strong, i.e. by increasing the passive and active knowledge of the students we might not be able to explicitly state that their creativity would be in higher levels as well. The different word frequency levels in three creativity groups were compared. As the results manifested, LC and MC participants' size of the passive lexical knowledge differed in total, academic and 10,000 levels, while these differences in the active lexical knowledge were observed in their vocabulary sizes of total, 5000 and 10,000 levels. In fact, it can be concluded that, 
as a whole MC participants knew more words than participants in LC group, but regarding each word frequency level the result differed.

MC and HC participants' lexical knowledge differed in none of the word frequency levels significantly. However, the most significant differences were observed in the comparisons between LC and $\mathrm{HC}$ groups. The analyses clearly illustrated the lack of strong correlation between creativity, lexical reception and production. It seems that creativity in higher levels can be a determining factor in reception and production of words. We may finally suggest that when creativity is considered as an individual variable in relation with lexical reception and production, it is significantly correlated with passive and active lexical knowledge, though this correlation is not a strong one.

\section{Theoretical Implications}

This current research has several theoretical implications. First, it highlights the effect of one of the psychological factors called creativity on lexical reception and production knowledge of L2 learners. Although this psychological factor is not a new notion in itself, it is seldom discussed in lexical research. One reason for the significant role of creativity in applied linguistics in general, compared to other factors could be that creativity as a construct is more proactively oriented than factors such as intelligence, motivation or aptitude (Hamidi, Wennberg, \& Berglund, 2008). While these factors might be good indicators of why some students succeed more in language learning, creativity may more specifically and proactively influence achievement in EFL learning context without considering that there could be a limit as to how far students could benefit in the field of applied linguistics. As a result it seems mandatory for theory makers of SLA or FLA to include this construct in the models of acquisition.

\section{Pedagogical Implications}

The outcomes of this study could be extended to the field of SLA, FLA and teaching. Regarding the proficiency, designing a syllabus in which the focus is based more on the proficiency of the L2 learners to improve the passive and active lexical knowledge is perhaps suggestive. With respect to the realm of lexical knowledge, what is of importance is the role that could be played by the educational system in reducing the gap between the two vocabulary types. A rough overview of some sample examination papers revealed that in most of the cases the passive knowledge of students is tested rather than their active knowledge (Zhiying \& Teo, 2010). This point, although not one of the aims of the present study, could be a good hint for other researchers to analyze in details the teaching system as well as the evaluation methods used in schools to find their possible role in reducing the gap between active and passive vocabulary knowledge.

Not long ago vocabulary was quite often, if not solely, taught through passive exercises such as memorizing long lists of words and their translations. This tradition has not yet been left out from our education system. The role of activities and instructional methods in vocabulary learning and teaching should be paid more attention to incorporate vocabulary teaching in teacher training courses. Informing teachers of the current research results and the implications of such research studies may influence and transform teachers in their beliefs and practice about teaching and learning vocabulary in a second or foreign language. Additionally, with a clear and definite goal in mind, teachers may attend to psychological and behavioral research in different tasks including vocabulary to improve their teaching.

Webb (2009) found that the kinds of tasks may have an effect on what second language learners can or cannot do with words receptively and productively, and receptive tasks such as providing definitions or translation or looking up words in a dictionary may help to increase receptive knowledge of words and improve comprehension, whereas productive tasks such as speaking or writing help enhance the productive knowledge of words. Therefore, depending on the goal of the task or program, different types of tasks could be utilized and a combination of both receptive and productive tasks may be most effective if the goal is to improve overall language skills (Webb, 2009). Raising the teachers' awareness of the fact that the types of tasks for vocabulary learning and teaching can have an influence on learning outcomes and performance of the students is also of critical importance for teacher trainers. Webb (2005) is reasonable when stating that vocabulary learning is likely to be receptive when it is taught in the class and teachers may only tell learners meanings or definitions of words or use them in sentences but they do not often ask them to use words except for spelling or pronunciation.

\section{References}

Abutalebi, J., \& Costa, A. (2008). Editorial, Acquisition, Processing and Loss of L2: Functional, cognitive and neural perspectives. Journal of Neurolinguistics, 21, 473-476. http://dx.doi.org/10.1016/j.jneuroling.2008.10.001

Aitchison, J. (1987). Words in the mind: An introduction to the mental lexicon. Oxford And New York: Basil Blackwell.

Albert, Á. (2006). Learner's creativity as a potentially important variable: Examining the relationships between learner creativity, language aptitude and level of proficiency. In M. Nikolov, \& J. Horváth (Eds.), Empirical studies 
in English applied linguistics (pp.77-98). Hungary: Eotuos University.

Albert, Á., Kormos, J. (2004). Creativity and narrative task performance: An exploratory study. Language Learning, 54, 277-310

Albert, Á., \& Kormos, J. (2011). Creativity and Narrative Task Performance: An Exploratory Study. Language Learning, 61(1), 73-99

Alderson, C. J. (2007). Judging the frequency of English words. Applied Linguistics, 28(3), 383-409. http://dx.doi.org/10.1093/applin/amm024

Altman, H. (1980). Foreign Language Teaching: Focus on the learner. In H. Altman, \& J. Vaughan (Eds.), Foreign language teaching: Meeting individual needs (pp.1-16). Oxford, Uk: Pergamon.

Anderson, R. C., \& Freebody, P. (1981). Vocabulary knowledge. In J. T. Guthrie (Ed.), Comprehension and teaching: Research reviews (pp. 77-117). Newark, DE: International Reading Association.

Brown, R. T. (1989). Creativity: What are we to measure? In J. A. Glover, R. R. Ronning, \& C. R. Reynolds (Eds.), Handbook of creativity (pp. 1-32). New York: Plenum Press.

Clapham, M. M. (2004). The Convergent Validity of the Torrance Tests of Creative Thinking and Creativity Interest Inventories. Educational and Psychological Measurement, 64(5), 828-841. http://dx.doi.org/10.1177/0013164404263883

Clark, E.V. (1993). The lexicon in acquisition. Cambridge, UK: Cambridge University Press.

Corson, D. (1997). The learning and use of academic English words. Language Learning, 47, 671-718

Coxhead, A. (2006). Essentials of teaching academic vocabulary. Boston, U.S.: Houghton Mifflin Company.

Dörnyei, Z. (2005). Motivational strategies in the language classroom. Cambridge: Cambridge University Press.

Ellis, R. (1994). The study of second language acquisition. Oxford, UK: Oxford University Press.

Fan, M. (2000). How Big is the Gap and How to Narrow it? An Investigation into the Active and Passive Vocabulary Knowledge of L2 Learners. RELC Journal, 31(2), 105-19. http://dx.doi.org/10.1177/003368820003100205

Fasko, D. J. (2001). Education and creativity. Creativity Research Journal, 13(3), 317-327

Finke, R. A., Ward, T. B., \& Smith, S. M. (1992). Creative cognition: Theory, research and applications. Cambridge, MA: MIT Press.

Fisher R. (2003). Teaching Thinking: Philosophical Enquiry in the Classroom. London: Continuum.

Golkar, M., Yamini, M. (2007). Vocabulary, proficiency, and reading comprehension. The Reading Matrix, 7, 88-112 Hadley, A. O. (2003). Teaching language in context. ( $3^{\text {rd }}$ ed.). Massachusettes: Heinle \& Heinle Publishers.

Hamidi, Y. D., Wennberg, K., \& Berglund, H. (2008). Creativity in entrepreneurship Education. Journal of Small Business and Enterprise Development, 15, 304-320

Hazenberg, S., Hulstijn, J. H. (1996). Defining a minimal receptive second language vocabulary for non-native university students: an empirical investigation. Applied Linguistics, 7, 145-163. http://dx.doi.org/10.1093/applin/17.2.145

Henriksen, B. (1999). Three dimensions of vocabulary development. Studies in Second Language Acquisition, 21, 303-317

Horst, M., Cobb, T., \& Nicolae, I. (2005). Expanding academic vocabulary with an interactive online database. Language Learning \& Technology. [Online] Available: http://ltt.msu.edu/vol9num2/horst/default.html (April 20, 2009)

Hsen, H. M. (2011). The effect size of variables associated with creativity: A meta-analysis. Creativity Research Journal, 21(1), 30-42, 2009

Hunt, A., \& Beglar, D. (2005). A framework for developing EFL reading vocabulary. Reading in a Foreign Language, 17, 1, 23-59

James, D. (1999). What does it mean to be creative? In K. Ashcroft, \& D. James (Eds.), The creative professional learning to teach 14-19 year- olds (pp. 8-28). New York: Taylor and Francis Group.

Kim, H. K. (2008). Commentary: The Torrance Tests of Creative Thinking already overcome many of the perceived weaknesses that Silvia et al.'s (2008) methods are intended to correct. Psychology of Aesthetics, Creativity, and the Arts, 2(2), 97-99 
Larsen-Freeman, D., \& Long, M. (1991). An introduction to second language acquisition research. London: Longman.

Laufer, B. (1998). The development of passive and active vocabulary in a second language: Same or different? Applied Linguistics, 19, 255-271

Laufer, B., Elder, C., Hill, K., \& Congdon, P. (2004). Size and strength: Do we need both to measure vocabulary knowledge? Language Testing, 21, 202-226

Laufer, B., \& Goldstein, Z. (2004). Testing vocabulary knowledge: Size, strength, and computer adaptiveness. Language Learning, 54(3), 399-436

Laufer, B., \& Nation, P. (1995). Vocabulary size and use: Lexical richness in L2 written production. Applied Linguistics, 16(3), 307-322

Laufer, B., \& Paribakht, T. S. (1998). The relationship between passive and active vocabularies: Effects of language learning context. Language Learning, 48(3). 365-391

Lee, S. L., \& Munice, J. (2006). From respective to productive: Improving ESL learners' use of vocabulary in a post-reading composition task. TESOL Quarterly, 40(2), 295-320. http://dx.doi.org/10.2307/40264524

Lewis, M. (2000). Introduction. In M. Lewis (Ed.), Teaching collocation. Further developments in the lexical approach (pp. 8-9). Hove: Language Teaching publications.

Liach, M. P. A., \& Gallego, M. T. (2009). Examining the Relationship between Receptive Vocabulary Size and Written Skills of Primary School Learners. ATLANTIS. Journal of the Spanish Association of Anglo-American Studies, 31(1), 129-147

Lubart, T. I. (1994). Creativity. In J. R. Sternberg (Ed.), Thinking and problem solving (pp. 289-332). San Diego: Academic Press.

Matsouka, O., Trevlas, E., \& Zachopoulou, E. (2003). Relationship between Playfulness and motor creativity in preschool children. Early childhood development and care, 173(5), 535-543

Meara, P. (1996). The dimensions of lexical competence. In G. Brown, K. Malmkjær, \& J. Williams (Eds.), Competence and performance in language learning (pp. 35-53). New York: Cambridge University Press.

Meara, P., \& Alcoy, C. O. J. (2010). Words as species: An alternative approach to estimating productive vocabulary size. Reading in a Foreign Language, 22, 222-236

Meara, P., \& Buxton, B. (1987). An Alternative to Multiple Choice Vocabulary Tests. Language Testing, 4(2), $142-51$

Meara, P., \& Fitzpatrick. T. (2000). Lex30: An Improved Method of Assessing Productive Vocabulary in an L2. System, 28, 19-30

Meara, P., \& Jones, G. (1990).Tests of Vocabulary Size in English as a Foreign Language. Polyglot, 8(1), 1-40

Mehotcheva, H. T. (2008). The Kruskal-Wallis Test. [Online] Available: http://www.Methodologyand statistics/Spss/One wayANOVA/html (May, 6, 2010)

Mokhtar, A. A. (2010). Vocabulary Knowledge of Adult ESL Learners. English Language Teaching, 3(1), 71-80

Morshedian, M. (2008). The role of Initial English language proficiency in lexical attrition/rRetention of Iranian learners: Is productive or the receptive word knowledge of learned nouns more likely to be lost? Linguistics Journal, 3(1), 75-99

Nasiri, R. (2008). How to work with SPSS 17. Tehran: Nashrgostar Publications.

Nation, I. S. P. (1990). Teaching and learning vocabulary. New York: Newbury.

Nation, I. S. P. (1993). Vocabulary size, growth and use. In R. Schreuder, and B. Weltens (ed), The Bilingual Lexicon (pp. 115-134). Amsterdam, Philadelphia: John Benjamins.

Nation, I. S. P. (2001). Learning vocabulary in another language. New York: Cambridge University Press.

Nation, I. S. P. (2005). Teaching vocabulary. Asian EFL Journal, 7(3), 47-54

Nemati, A. (2010). Active and passive vocabulary knowledge: The effect of years of instruction. The Asian EFL Journal Quarterly, 12, 30-46

Ottó, I. (1998). The relationship between individual differences in learner creativity and language learning success.

TESOL Quarterly, 32, 763-773. http://dx.doi.org/10.2307/3588011 
Qian, D. (1999). Assessing the role of depth and breadth of vocabulary knowledge in Reading comprehension. The Canadian Language Review, 56, 282-308

Qian, D. (2002). Investigating the relationship between vocabulary knowledge and academic reading performance: An assessment perspective. Language Learning, 56, 513-536

Qian, D. (2004). Establishing parameters for assessing vocabulary knowledge. Language Assessment Quarterly, 1(1), 57-61

Read, J. (2000). Assessing vocabulary. New York: Cambridge University Press.

Schmitt, N. (2000). Vocabulary in language teaching. Cambridge: Cambridge University Press.

Schmitt, N., Schmitt, D., \& Clapham, C. (2001). Developing and exploring the behavior of two new versions of the Vocabulary Levels Test. Language Testing, 18(1), 55-88

Segalowitz, N. (1997). Individual differences in second language acquisition. In A. de Groot, \& J. Kroll (Eds.), Tutorials in bilingualism. (pp. 85-112). IIillsdale, NJ: Lawrance Erlbaum Associates.

Segler, T. (2001). Second language vocabulary acquisition and learning strategies in ICALL environments. [Online] Available: http://www.teachereducation.com/html_(June, 25, 2009)

Skehan, P. (1989). Individual differences in second language learning. London: Edward Arnold.

Sternberg, R. J. (1985). Beyond IQ: A triarchic theory of human intelligence. NewYork: Cambridge University Press.

Torrance, E. P. (1984). The role of creativity in identification of the gifted and talented. Gifted Child Quarterly, $28,153-156$

Torrance, E. P. (1990). The Torrance tests of creative thinking norms-technical Manual figural (streamlined) forms A \& B. Bensenville. IL: Scholastic Testing Service, Inc.

Waring, R. (1997). A study of receptive and productive vocabulary learning from word cards. [Online] Available: http://www1.harenet.ne.jp/waring/papers/papers.html (March, 13, 2010)

Webb, S. (2005). Receptive and productive vocabulary learning: The effects of reading and writing on word knowledge. Studies in Second Language Acquisition, 27, 33-52

Webb, S. (2008). Receptive and productive vocabulary sizes of L2 learners. Studies in Second Language Acquisition, $30,79-95$

Webb, S. (2009). The effects of pre-learning vocabulary on reading comprehension and writing. The Canadian Modern Language Review, 65, 3, 411-470

Wilkins, D. (1972). Linguistics in language teaching. London: Arnold.

Zareva, A., Schwanenflugel, P., \& Nikolova, Y. (2005). Relationship between lexical competence and language proficiency. Studies in Second Language Acquisition, 27, 567-595. http://dx.doi.org/10.1017/S0272263105050254

Zhiying, Z., \& Teo, A. (2010). A comparative study of passive and active vocabulary knowledge of prince of Songkla University and South China Agricultural University EFL Learners. [Online] Available: http://www.human.pn.psu.ac.th/ojs/index.php/eJHUSO/article/view/21/31 (May, 17, 2009)

Zimmerman, C. B. (1997). Historical trends in second language instruction. In J. Coady, \& T., Huckin (Eds.), Second language vocabulary acquisition (pp. 5-19). Cambridge University Press.

Table 1. Descriptive statistics of TTCT

\begin{tabular}{|c|c|c|c|c|c|c|c|c|}
\hline $\begin{array}{l}\mathbf{N} \\
\text { valid }\end{array}$ & 局 & $\begin{array}{l}\text { ह్ } \\
\stackrel{\Xi}{\Xi}\end{array}$ & & $\begin{array}{l}\stackrel{0}{g} \\
\stackrel{g}{g}\end{array}$ & $\stackrel{\ominus}{\dot{\infty}}$ & 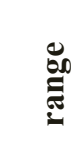 & 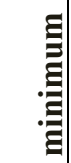 & 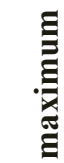 \\
\hline 141 & 0 & 79.36 & 79.00 & 79 & 13.639 & 71 & 44 & 115 \\
\hline
\end{tabular}


Table 2. The frequency of TTCT scores at different levels of creativity

\begin{tabular}{|l|l|l|l|}
\hline \multirow{2}{*}{} & \multicolumn{3}{|c|}{ Creativity level/group } \\
\cline { 2 - 4 } & Low & Medium & High \\
\hline Frequency & 51 & 41 & 49 \\
\hline Percentage & 36.20 & 29.10 & 34.80 \\
\hline
\end{tabular}

Table 3. Descriptive statistics of different levels of TTCT

\begin{tabular}{|c|c|c|c|c|c|c|c|}
\hline \multirow{2}{*}{} & & $\mathbf{N}$ & Range & Minimum & Maximum & Mean & S.D \\
\cline { 2 - 9 } & Low & 51 & 33.00 & 44.00 & 77.00 & 66.28 & 6.66 \\
\cline { 2 - 9 } & Medium & 41 & 27.00 & 57.00 & 84.00 & 78.43 & 4.41 \\
\cline { 2 - 9 } & High & 49 & 71 & 85.00 & 115.00 & 94.20 & 7.11 \\
\hline
\end{tabular}

Table 4. Comparison between creativity groups in pairs based on their creativity scores

\begin{tabular}{|c|c|c|c|c|c|c|}
\hline & & $\mathbf{N}$ & $\begin{array}{c}\text { Mean } \\
(M)\end{array}$ & S.D & $\begin{array}{c}\text { Mean } \\
\text { Difference }\end{array}$ & Sig \\
\hline \multirow{6}{*}{ 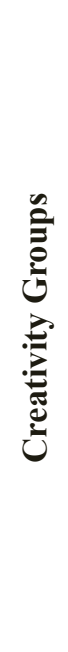 } & Low & 51 & 65.84 & 7.30 & \multirow[t]{2}{*}{-12.59} & \multirow[t]{2}{*}{.000} \\
\hline & Medium & 41 & 78.44 & 4.41 & & \\
\hline & Low & 51 & 65.84 & 7.30 & \multirow[b]{2}{*}{-28.36} & \multirow[b]{2}{*}{.000} \\
\hline & High & 49 & 94.20 & 7.11 & & \\
\hline & Medium & 41 & 78.44 & 4.41 & \multirow[b]{2}{*}{-15.76} & \multirow[b]{2}{*}{.000} \\
\hline & High & 49 & 94.20 & 7.11 & & \\
\hline
\end{tabular}

Table 5. Descriptive statistics of passive and active tests

\begin{tabular}{|c|c|c|c|c|c|c|c|c|c|}
\hline Tests & $\frac{\bar{g}}{\pi} \mathrm{z}$ & 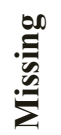 & $\sum_{\bar{E}}^{\bar{E}}$ & & 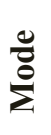 & $\stackrel{\oplus}{\dot{s}}$ & $\begin{array}{l}\mathscr{E} \\
\stackrel{\mathscr{E}}{\tilde{E}} \\
\simeq\end{array}$ & $\stackrel{\Xi}{\Sigma}$ & $\sum_{\Sigma}^{\stackrel{J}{\Sigma}}$ \\
\hline Passive & 141 & 0 & 95.76 & 98.00 & 97 & 23.13 & 100 & 38 & 138 \\
\hline Active & 141 & 0 & 44.87 & 46.00 & 38 & 15.68 & 69 & 11 & 80 \\
\hline
\end{tabular}


Table 6. Descriptive statistics of different word levels of active and passive tests

\begin{tabular}{|c|c|c|c|c|c|c|c|c|}
\hline & \multirow[t]{2}{*}{ Test } & \multirow{2}{*}{$\begin{array}{l}\text { NO } \\
\text { items }\end{array}$} & \multirow[b]{2}{*}{ Range } & \multirow[b]{2}{*}{ Min } & \multirow[b]{2}{*}{ Max } & \multicolumn{2}{|c|}{ Mean } & \multirow[b]{2}{*}{ S.D } \\
\hline & & & & & & Raw & $\%$ & \\
\hline \multirow{6}{*}{$\frac{\sqrt{x}}{\sqrt{2}}$} & Total & 150 & 100 & 38 & 138 & 95.76 & 63.84 & 23.13 \\
\hline & 2000 & 30 & 17 & 13 & 30 & 27.38 & 91.26 & 3.29 \\
\hline & 3000 & 30 & 28 & 2 & 30 & 23.60 & 78.66 & 5.20 \\
\hline & 5000 & 30 & 21 & 9 & 30 & 22.76 & 75.86 & 6.38 \\
\hline & UWL & 30 & 28 & 2 & 30 & 16.91 & 56.36 & 7.18 \\
\hline & 10000 & 30 & 20 & 0 & 20 & 5.10 & 17.00 & 5.12 \\
\hline \multirow{6}{*}{$\sum^{v}$} & Total & 90 & 69 & 11 & 80 & 44.87 & 49.85 & 15.68 \\
\hline & 2000 & 18 & 16 & 2 & 18 & 14.14 & 78.55 & 3.23 \\
\hline & 3000 & 18 & 17 & 1 & 18 & 9.22 & 51.22 & 4.23 \\
\hline & 5000 & 18 & 15 & 1 & 16 & 9.00 & 50.00 & 3.43 \\
\hline & UWL & 18 & 17 & 0 & 17 & 9.06 & 50.33 & 4.16 \\
\hline & 10000 & 18 & 12 & 0 & 12 & 3.32 & 18.44 & 2.90 \\
\hline
\end{tabular}

Table 7. Descriptive statistics of passive and active vocabulary levels

\begin{tabular}{|c|l|l|l|l|l|l|}
\hline \multicolumn{2}{|c|}{} & Range & Minimum & Maximum & Mean $(\boldsymbol{M})$ & S.D \\
\hline $\begin{array}{c}\text { Vocabulary } \\
\text { Levels }\end{array}$ & Passive & 6212.12 & 2803.03 & 9015.15 & 6172.14 & 1494.61 \\
\cline { 2 - 7 } & Active & 7525.25 & 1085.86 & 8611.11 & 4698.93 & 1648.67 \\
\hline
\end{tabular}

Table 8. Pearson Correlation Coefficient between Creativity and Lexical Reception

\begin{tabular}{|c|c|c|c|}
\hline & N & Correlation & Sig (2-tailed) \\
\hline Creativity & 141 & & \\
\cline { 1 - 2 } Passive Lexical Knowledge & 141 & $0.259 * *$ & .002 \\
\hline
\end{tabular}

** Correlation is significant at .05 level

Table 9. Pearson Correlation Coefficient between Creativity and Lexical Production

\begin{tabular}{|l|c|l|c|}
\hline & N & Correlation & Sig (2-tailed) \\
\hline Creativity & 141 & \multirow{2}{*}{$0.279^{* *}$} & .002 \\
\hline Passive score & 141 & & \\
\hline
\end{tabular}

** Correlation is significant at 0.01 level

Table 10. Descriptive statistics and post hoc testes results of active and passive levels

\begin{tabular}{|c|c|c|c|c|c|c|c|}
\hline ב্] & $\begin{array}{l}\text { Post } \\
\text { hoc }\end{array}$ & $\begin{array}{c}\text { Creativity } \\
\text { Groups }\end{array}$ & Mean & S.D & $\begin{array}{c}\text { Creativity } \\
\text { Groups }\end{array}$ & $\begin{array}{c}\text { Mean } \\
\text { Difference }\end{array}$ & Sig \\
\hline & \multirow{3}{*}{ 冚 } & Low & 5645.87 & 1216.99 & Low / Med & $-739.93 *$ & .033 \\
\hline & & Medium & 6385.80 & 1458.21 & Med / High & -155.31 & .948 \\
\hline & & High & 6541.12 & 1555.09 & Low / High & $-895.25^{*}$ & .006 \\
\hline \multirow{3}{*}{ 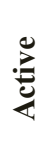 } & \multirow{3}{*}{ 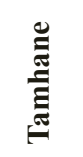 } & Low & 4129.03 & 1213.16 & Low / Med & $-806.90 *$ & .033 \\
\hline & & Medium & 4935.94 & 1658.24 & Med / High & -157.85 & .965 \\
\hline & & High & 5093.79 & 1884. 3 & Low / High & $-964.75^{*}$ & .010 \\
\hline
\end{tabular}




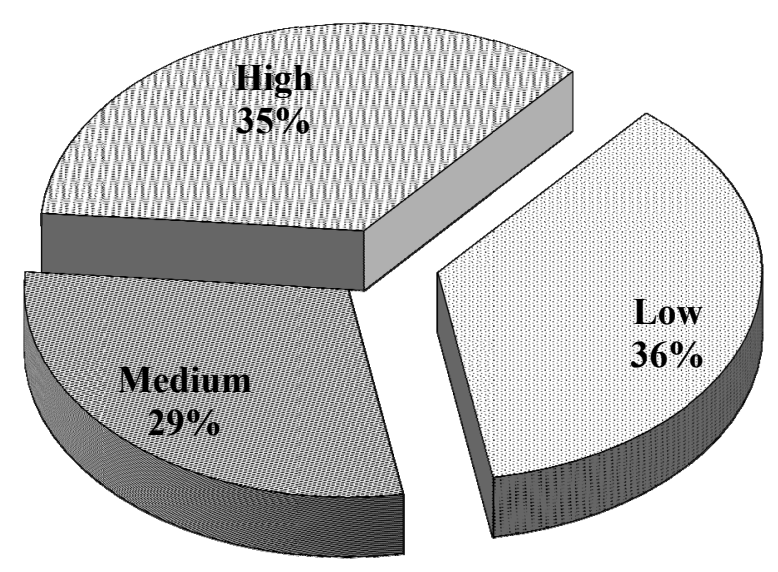

Figure 1. The participants' percentage at creativity levels

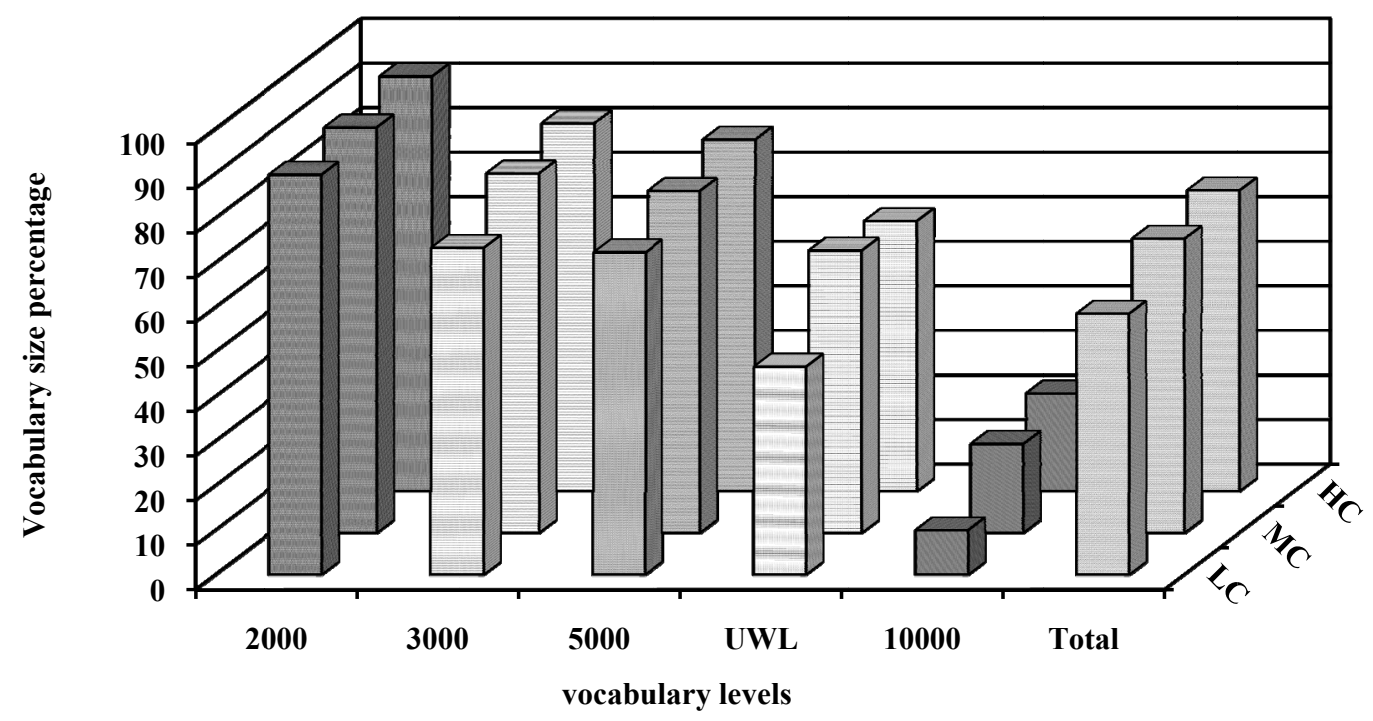

Figure 2. Passive vocabulary size at creativity levels 


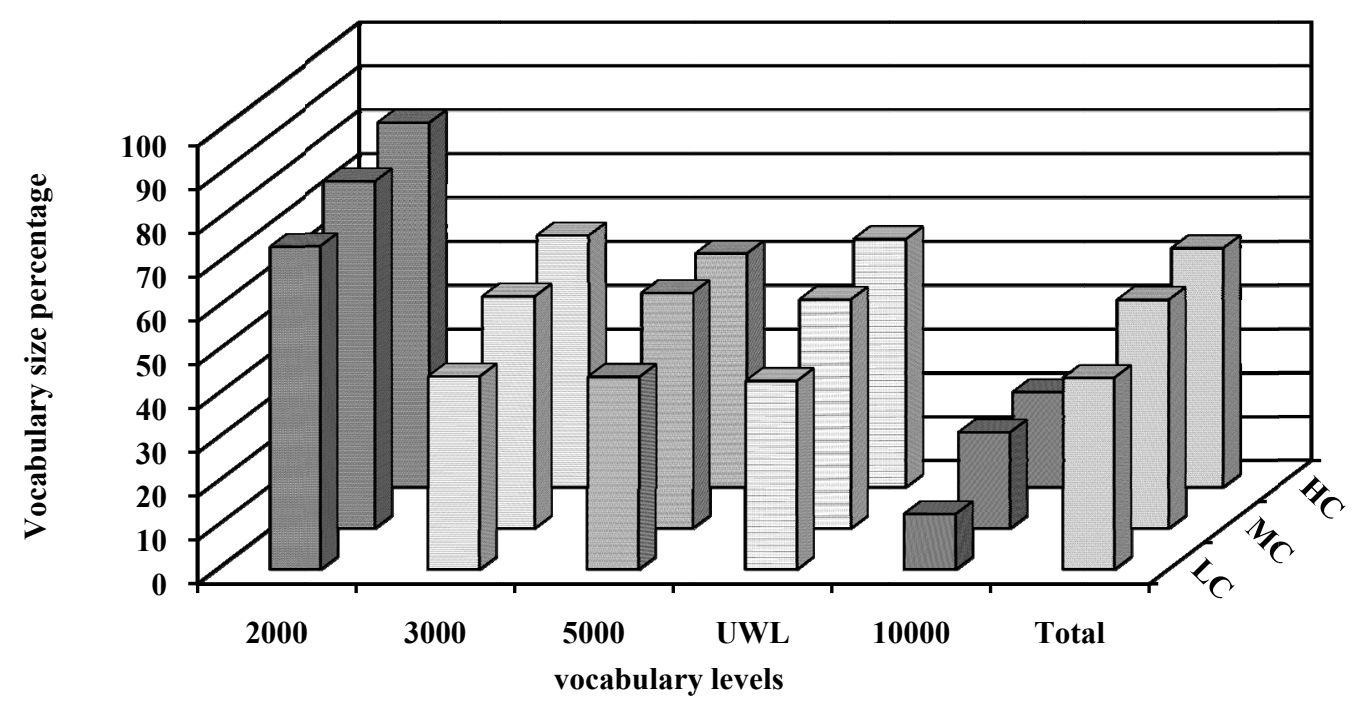

Figure 3. Active vocabulary size at creativity levels

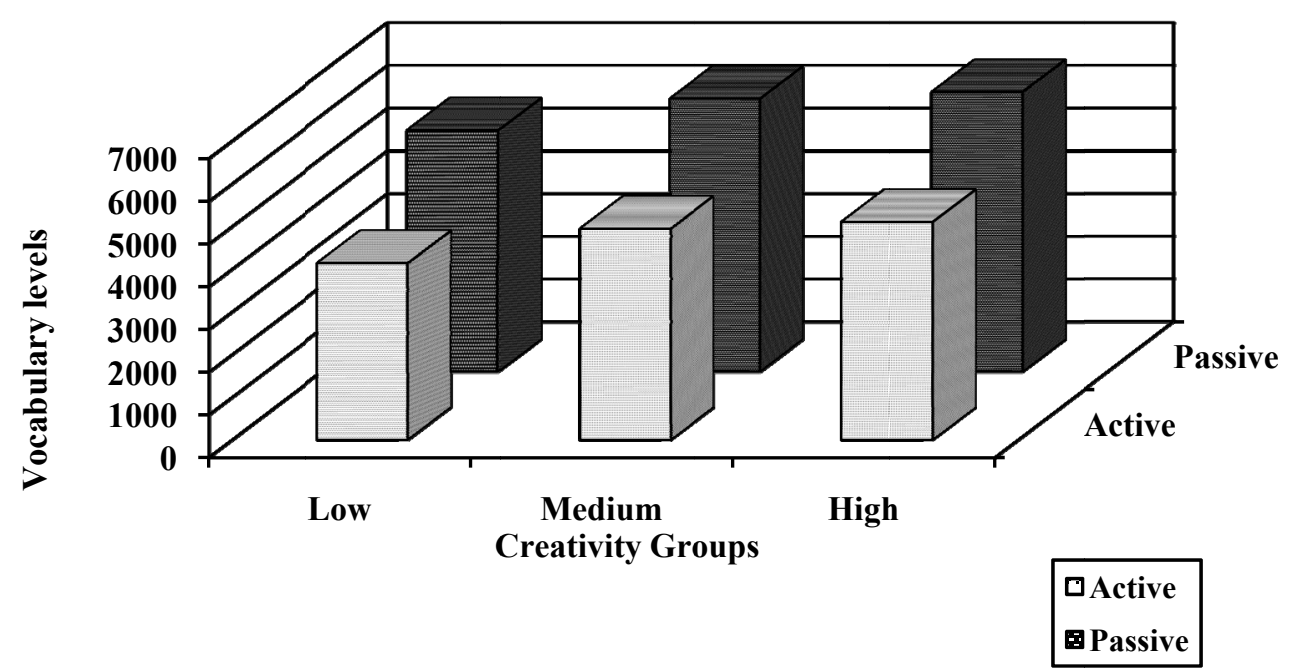

Figure 4. Passive and active levels at creativity groups 